\title{
Psychosocial Well-being of Siblings of Adolescents with Anorexia Nervosa
}

\section{AUTHORS:}

Tanja van Langenberg ${ }^{1}$, Susan M. Sawyer, ${ }^{2-4}$, Daniel Le Grange ${ }^{2,3,5}$ \& Elizabeth K. Hughes, ${ }^{1-}$

4

${ }^{1}$ School of Psychological Sciences, Monash University, Clayton, VIC, Australia

${ }^{2}$ Department of Paediatrics, The University of Melbourne, Australia

${ }^{3}$ The Royal Children's Hospital Centre for Adolescent Health, Parkville, VIC, Australia

${ }^{4}$ Murdoch Childrens Research Institute, Parkville, VIC, Australia

${ }^{5}$ Department of Psychiatry and Department of Pediatrics, University of California San

Francisco, San Francisco, CA, USA

\section{CORRESPONDING AUTHOR:}

Dr Elizabeth Hughes, PhD

Centre for Adolescent Health, The Royal Children's Hospital

50 Flemington Rd, Parkville, Victoria, 3052, Australia.

Tel: +61393454738

Fax: +61393456343

Email: Libby.Hughes@rch.org.au

This is the author manuscript accepted for publication and has undergone full peer review but has not been through the copyediting, typesetting, pagination and proofreading process, which may lead to differences between this version and the Version of Record. Please cite this article as doi: $10.1002 /$ erv.2469

This article is protected by copyright. All rights reserved. 


\section{Abstract}

Anorexia Nervosa (AN) is often first diagnosed in the adolescent years. The treatment with the greatest support during this time is family-based treatment (FBT). In FBT, siblings are expected to attend treatment sessions, however, sibling well-being during this time has not been well researched. This study aimed to explore sibling well-being when the ill child was initially diagnosed with AN and after FBT had been completed. Method: 85 parents and 55 siblings of adolescents with AN completed The Strengths and Difficulties Questionnaire (SDQ) at diagnosis. In addition, 88 parents and 46 siblings completed the SDQ after finishing treatment. Results: Mothers and fathers reported siblings to have lower levels of conduct problems in comparison to population norms. Mothers also reported lower levels of prosocial behaviours. Siblings reported higher levels of emotional difficulties and hyperactivity in comparison to their peers. There were no differences in reported psychosocial well-being of siblings between diagnosis and following FBT. Conclusions: Siblings of adolescents with AN have poorer psychosocial adjustment than their peers, both before and after FBT. Clinicians and parents are encouraged to be aware of sibling difficulties and seek additional support if required.

This article is protected by copyright. All rights reserved. 
Keywords: anorexia nervosa, eating disorders, family-based treatment, siblings, psychosocial well-being

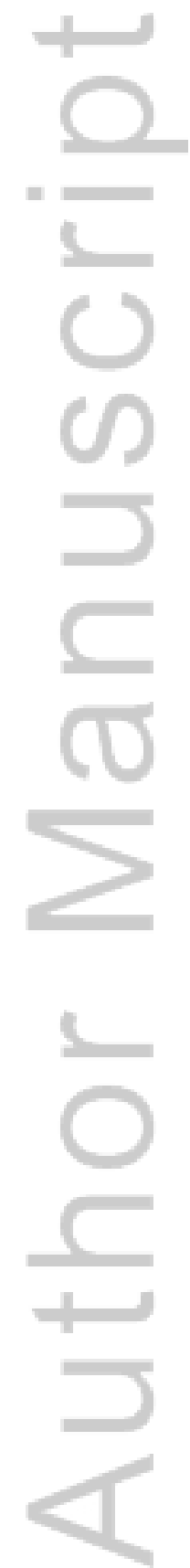

This article is protected by copyright. All rights reserved. 


\section{Psychosocial Well-being of Siblings of Adolescents with Anorexia Nervosa}

Anorexia Nervosa (AN) is a complex and serious psychiatric disorder, with significant psychological, physical, social and emotional difficulties. The effects of

$\mathrm{AN}$ on the patient have been well documented (Bulik, Sullivan, Fear, \& Joyce, 1997; Bulik et al., 2006; Herzog, Keller, Sacks, Yeh, \& Lavori, 1992; Mitchell \& Crow, 2006; Sullivan, Bulik, Fear, \& Pickering, 1998), however the effects of the illness on the family, in particular the siblings, have not been thoroughly studied. This is surprising given that AN usually has its onset during adolescence (Hoek \& van

Hoeken, 2003; Swanson, Crow, Le Grange, Swendsen, \& Merikangas, 2011) and that treatment for adolescent AN often involves the family, including siblings (Lock \& Le Grange, 2013).

Most of the limited research exploring the sibling experience of AN, has been qualitative and has highlighted a mixture of positive and negative aspects. Analysis of qualitative interviews with unaffected siblings indicates that some have difficulties coping with AN, experience the illness as a pervasive phenomenon in their lives, and that AN affects their relationships both within and outside of the family (Garley \& Johnson, 1994). Patients themselves have also described experiencing strained sibling relationships (Bachner-Melman, 2005; Honey, Clarke, Halse, Kohn, \& Madden, 2006). In the only available quantitative study, 16 out of 20 participating siblings reported poorer quality of life related to the onset of their sibling's eating disorder

(Areemit, Katzman, Pinhas, \& Kaufman, 2010). Conversely, other qualitative studies 
have noted that, in addition to difficulties, siblings often report positive experiences such as developing a greater understanding of mental illness and closer sibling relationships (Dimitropoulos, Klopfer, Lazar, \& Schacter, 2009; Withers et al., 2013).

Beyond the field of eating disorders, there is a larger body of research with families of children diagnosed with a severe or chronic illness that has demonstrated that living with an ill child can have a broad range of effects on siblings. For example, children with a chronically ill sibling have been reported to experience greater depression, anxiety, and emotional problems and poorer self-concept than control groups (Del Rosario \& Keefe, 2003; Ferrari, 1987; Powell \& Gallagher, 1993; Sharpe \& Rossiter, 2002; Tritt \& Esses, 1988) or compared to population norms (Del Rosario \& Keefe, 2003; Giallo \& Gavidia-Payne, 2006; Powell \& Gallagher, 1993; Sharpe \& Rossiter, 2002; Wood et al., 1988). Siblings of individuals diagnosed with mental health difficulties, such as schizophrenia, have reported experiencing an emotional burden (Karp \& Tanarugsachock, 2000), engaging in maladaptive coping strategies (Lively, Friedrich, \& Rubenstein, 2004), and having to provide caregiving to their ill sibling (Barnable, Gaudine, Bennett, \& Meadus, 2006). Notably, mental illness appears to be particularly stressful for siblings compared to intellectual disabilities and medical illnesses (Marsh et al., 1994; Moorman, 1992; Seltzer, Greenberg, Krauss, Gordon, \& Judge, 1997).

Research has also highlighted positive effects of chronic illness on the well-being of unaffected siblings, such as increased sensitivity, compassion, independence, empathy, maturity, family closeness and social competence (Alderfer et al., 2010;

This article is protected by copyright. All rights reserved. 
Bellin \& Kovacs, 2006; Bendor, 1990; Faux, 1991, 1993; Ferrari, 1983; Horwitz \& Kazak, 1990; Kramer, 1984; Labay \& Walco, 2004; McHale, Sloan, \& Simeonsson, 1986; Sloper, 2000). However, in an overview of existing literature, including systematic reviews and meta-analyses, Barlow and Ellard (2006) concluded that the impact of an ill child on siblings remains unclear. This uncertainty is likely due to heterogeneity among types of illnesses studied, stage of illness, and specific areas of functioning assessed. It is for this reason that illness-specific research can be particularly valuable in helping understand the unique needs and well-being of siblings of adolescents with AN.

Whilst different forms of individual and family therapy are used in the treatment of adolescents with AN (Lock, 2015), several clinical trials have suggested that family-based treatment (FBT) is an effective treatment for medically stable adolescents (Eisler, Simic, Russell, \& Dare, 2007; Lock et al., 2010; Robin, Siegel, Koepke, Moye, \& Tice, 1994; Robin et al., 1999; Russell, Szmukler, Dare, \& Eisler, 1987). For the purposes of this research paper, FBT refers to the approach originally developed at the Maudsley Hospital, London, and later manualised by Lock and Le Grange (Dare, Eisler, Russell, \& Szmukler, 1990; Lock \& Le Grange, 2013; Russell et al., 1987). FBT is an outpatient treatment in which the family is seen as a resource, and plays an important part in supporting the adolescent's recovery (Lock \& Le Grange, 2013). All family members are expected to be involved in the treatment process, with siblings expected to attend treatment sessions and provide emotional support to their ill brother or sister at home. 
FBT may be effective for recovery from AN; however, the process can be very distressing for patients as they face their fears of eating and weight gain. It can also be distressing for parents as they try to support their oftentimes resistant child in these efforts. In turn, FBT may place stress on siblings; for example, through exposure to their family members' distress and conflict, or through their own attempts to support their brother/sister. The potential deleterious side-effects of FBT for sibling wellbeing are particularly important given that relatives of individuals with $\mathrm{AN}$ are already at higher risk for psychopathology (Lilenfeld, Kaye, Greeno, \& et al., 1998). Qualitative research suggests that families are concerned about the impact of AN and FBT on siblings (Withers et al., 2013); however, there has been no quantitative study of sibling well-being within an FBT program. Of importance, there is evidence that family functioning actually improves during FBT (Ciao, Accurso, Fitzsimmons-Craft, Lock, \& Le Grange, 2014). Thus, an alternative possibility is that sibling well-being could likewise improve during FBT. Understanding sibling well-being within this context would help guide clinical decision-making regarding the levels of sibling involvement in the treatment process.

In summary, previous research has shown that siblings of children with chronic illness and mental health difficulties have a range of both positive and negative experiences. Some similar findings exist with regard to the siblings of individuals with AN, but research is scarce and largely qualitative (Areemit et al., 2010; BachnerMelman, 2005; Dimitropoulos et al., 2009; Garley \& Johnson, 1994; Honey et al., 2006; Honey \& Halse, 2007; Withers et al., 2013). There is no quantitative research 
with siblings of adolescents involved in family therapy for AN, despite FBT becoming one of the most widely used, and empirically validated treatments for medically stable adolescents with AN (Lock, 2015). The present study therefore aimed to explore the psychosocial well-being of siblings of adolescents with AN at a specialist paediatric eating disorder service. Sibling well-being was assessed at diagnosis and following treatment using the parent- and self-reported Strengths and Difficulties Questionnaire (Goodman, 2001). Parents, patients, and siblings also rated their expectation of the impact of treatment on the sibling's well-being (at diagnosis), and their perception of the impact of treatment of the sibling's well-being (following treatment). Based on previous research, it was expected that sibling well-being at diagnosis would be poorer compared to population norms. It was also expected that poorer sibling wellbeing at diagnosis would be related to greater severity of patient illness (i.e, lower weight, longer duration, psychiatric comorbidity, hospitalised at presentation). Given the lack of prior research, no hypotheses were made regarding sibling well-being following FBT, or regarding family members' ratings of expected and perceived impact.

\section{Method}

\section{Setting}

The current study was conducted at The Royal Children's Hospital (RCH) Eating Disorders Program in Melbourne, Australia. The multidisciplinary program offers outpatient FBT to families of children and adolescents diagnosed with AN or Eating

This article is protected by copyright. All rights reserved. 
Disorder Not Otherwise Specified-AN type (EDNOS-AN; American Psychiatric Association, 2000) ${ }^{1}$. FBT is conducted across 18 sessions, over approximately 6 months. Trained mental health clinicians under the supervision of the third author deliver FBT.

\section{Participants}

All families of AN patients attending the eating disorders program who had at least one sibling were invited to take part in this study. In multi-sibling families, all siblings over the age of 10 were eligible to participate. Following a diagnostic assessment, and prior to starting treatment, all family members (i.e., patients, siblings, and parents) were invited to complete a questionnaire. During the recruitment period (June 2011 - July 2014), 126 families were invited to take part in the study. A total of 85 parents (47 mothers, 38 fathers), 46 patients, and 55 siblings completed questionnaire at diagnosis.

All family members (i.e., patients, siblings, and parents) of adolescents who completed FBT during the recruitment period were invited to complete a questionnaire. Families who withdrew from treatment or had not completed treatment by the end of the recruitment period were ineligible to take part in the study. Of the 84 eligible families, 88 parents (64 mothers, 24 fathers), 38 patients and 46 siblings completed the questionnaires.

\footnotetext{
${ }^{1}$ DSM-IV was used for the current study as this was the classification system in effect for the study period. Hereafter, AN and EDNOS-AN are referred to collectively as AN.
} 
Demographic data of participants in this study are outlined in Table 1. The participants represented a total of 89 families of adolescents with AN. Of these adolescent patients, $32(36 \%)$ had EDNOS-AN and 80 (90\%) were female. Their mean age was 15.1 years $(\mathrm{SD}=1.8)$ and mean duration of illness was 9.2 months $(\mathrm{SD}$ $=6.8$ ). Psychiatric comorbidity was present for $44 \%$ of patients (most commonly anxiety and depressive disorders), and $40 \%$ were admitted for inpatient medical stabilisation prior to commencing FBT. Thirty percent of patients had family members who completed surveys both at diagnosis and following treatment, while $32 \%$ and $38 \%$ had family members who completed surveys only at diagnosis or following treatment, respectively.

\section{[Insert Table 1 here]}

\section{Procedure}

All patients attended an intake diagnostic assessment with their parents prior to starting treatment. Siblings do not attend this assessment. At the end of this assessment, eligible families were provided with information statements about the study and how to access online surveys. Families who had already completed FBT

during the recruitment period were mailed a letter briefly introducing the study. A researcher then phoned the parents and either emailed links to the online questionnaires or mailed a hardcopy of the questionnaire depending on family preference. Families were invited to participate following treatment even if they had 
not participated at diagnosis (i.e., due to recruitment not yet commencing, or due to failure to complete the surveys before starting treatment).

The RCH and Monash University Human Research Ethics Committees approved the study. Information statements were supplied to participants and consent was implied through completion of the questionnaires.

\section{Measures}

The Strengths and Difficulties Questionnaire (SDQ) is a 25-item measure for assessing the psychological adjustment of children and youth (Goodman, 2001). The 25 items are divided amongst five scales measuring: Emotional Difficulties, Conduct Problems, Hyperactivity/Inattention, Peer Problems, and Prosocial Behaviour. A Total Difficulties score is also computed. Respondents use a 3-point Likert scale to indicate how much each attribute applies to themselves (self-report) or to the target child (parent version). Responses were recorded as $1=$ Not True, $2=$ Somewhat True or 3 $=$ Certainly True. Siblings completed the SDQ about their own functioning and parents completed the SDQ about the target sibling's functioning. For multi-sibling families, parents could complete separate questionnaires for each sibling. The SDQ has good internal consistency (mean Cronbach $\alpha=.73$ ), cross-informant correlation

$($ mean $=0.34)$, and retest stability after 4 to 6 months $($ mean $=0.62 ;$ Goodman, 2001) In the current study, the Cronbach alpha coefficients for parents and siblings, respectively, were: Emotional Difficulties $=.84$ and .75 , Conduct Problems $=.53$ and 
.68 , Hyperactivity/Inattention $=.65$ and .66 , Peer Problems $=.63$ and .67 , Prosocial Behaviour $=.44$ and .70 , and Total Difficulties $=.84$ and .86

At diagnosis, and prior to commencing treatment, parents, patients and siblings answered the following study-specific question: "Do you think [the patient]'s treatment will affect [the sibling]'s overall well-being?". Responses were provided on a 7-point Likert scale, with -3 indicating a "Very negative effect", 0 indicating "No effect", and +3 indicating a "Very positive effect". In the questionnaire completed following treatment, parents, patients, and siblings were asked "Do you think [the patient]'s treatment has affected [the sibling]'s overall well-being?" with the same accompanying response scale. Responses were collapsed into three categories:

Negative Effect (small negative effect; moderate negative effect; very negative effective), No Effect, and Positive Effect (small positive effect; moderate positive effect; very positive effective).

\section{Data Analysis}

All analyses were performed with SPSS version 17.0 and GraphPad Software QuickCals (http://www.graphpad.com/). Mean SDQ scores were compared to population norms published on the SDQ website (http://www.sdqinfo.org/) using independent sample t-tests, where a $\mathrm{p}$ value of less that .05 was used to determine significantly significant results. The published norms comprised means and standard deviations obtained from 910 parent-reports and 553 self-reports of Australians aged 11 to 17 years (males and females combined). One-way analysis of variance 
(ANOVA) was used to compare participant SDQ scores at diagnosis and following treatment. Relationships between reported sibling well-being and illness severity were examined using Pearson correlation coefficients for continuous indicators of severity (i.e., percent of median BMI (\%mBMI) at diagnosis, duration of illness) and t-tests for categorical indicators (i.e., comorbid psychiatric condition, hospitalised at presentation). Chi square analysis was used to compare parent, patient, and sibling expectations of the effect of patient's treatment on sibling well-being at diagnosis to their perceptions of its effect following treatment.

\section{Results}

Means and standard deviations for the SDQ at diagnosis and following treatment were compared to population norms as shown in Table $2^{2}$. At diagnosis, siblings reported higher levels of emotional difficulties, hyperactivity/inattention, and total difficulties in comparison to the population norms. Mothers reported that siblings had lower levels of conduct problems and lower levels of prosocial behaviours compared to population norms. Fathers also reported lower levels of sibling conduct problems compared to norms. There were no other significant differences between participant SDQ scores at diagnosis and populations norms.

\footnotetext{
${ }^{2}$ Due to the sample size, males and females were combined for the analysis despite some sex differences in mean subscale scores. Mother's reported that female siblings had higher Emotional Difficulties than male siblings at diagnosis and following treatment $(p<.05)$. Female siblings self-reported more Emotional, Conduct, Hyperactivity and Peer problems than did male siblings at diagnosis $(p<.05)$. There were no other significant sex differences.
} 
Following treatment, siblings endorsed experiencing higher levels of emotional difficulties, hyperactivity/inattention, peer problems and total difficulties compared to norms. Mothers reported that siblings had higher levels of emotional difficulties and lower levels of prosocial behaviours compared to norms. Fathers also reported siblings to have lower levels of prosocial behaviours compared to norms. There were no other significant differences between participant SDQ scores following treatment and populations norms.

A one-way ANOVA was conducted to explore whether sibling self-reported and parent-reported SDQ scores at diagnosis differed significantly from those following treatment. No significant differences were found.

\author{
[Insert Table 2 here]
}

Pearson correlations between SDQ scores at diagnosis and patient \% mBMI and duration of illness are shown in Table 3. There were no significant correlations for patient $\% \mathrm{mBMI}$. There were several significant correlations for duration of illness. With a few exceptions, longer duration of illness was associated with more emotional difficulties, peer problems and total difficulties as reported by mothers, fathers and siblings ( $r$ range $=.24$ to $.49, p<.05$ ) and lower prosocial behaviours as reported by fathers $(r=-.32, p<.05)$. SDQ scores differed significantly by patient psychiatric comorbidity status for just one subscale. At diagnosis, fathers reported lower conduct problems for siblings of patients with a comorbidity $(M=0.50, S D=0.51)$ than

This article is protected by copyright. All rights reserved. 
without $(M=1.14, S D=1.17), t(59)=2.63, p<.05)$. Differences in SDQ scores by patient hospitalisation status are shown in Table 4. Overall, they indicate that siblings of patients who are hospitalised for medical stability prior to FBT had lower emotional difficulties and total difficulties according to all three reporters, and lower hyperactivity/inattention as self-reported by siblings (all $p s<.05$ ). Given the seemingly contradictory findings for duration of illness and hospitalisation, the relationship between these two indicators of severity was examined. There was a tendency for patients who were hospitalised to have a shorter duration of illness $(M=$ 7.8 months, $S D=4.8)$ than those who were not $(M=10.1, S D=7.8)$ although this fell short of statistical significance $(t(86)=1.76, p=.082)$.

[Insert Tables 3 and 4 here]

The percentage of siblings and parents who reported that treatment would have, or did have, a negative effect, no effect, or positive effect on sibling well-being is presented in Table 5. A chi square analysis was conducted to compare family member's expectation of treatment effects on siblings at diagnosis to perceived effects following treatment. There were no significant differences between time points for siblings, mothers, father, or patients.

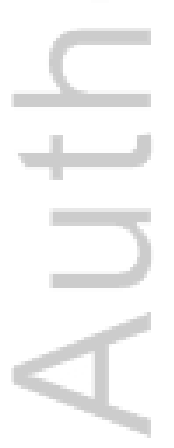

[Insert Tables 5 here] 


\section{Discussion}

This is the first study to provide quantitative data on the psychosocial wellbeing of siblings of adolescents with AN who have been engaged in FBT. The study found that despite concerns by some family members about the negative impact of treatment on sibling well-being, this was generally not supported when assessed with a widely utilised, standardised measure (i.e., the SDQ). Siblings self-reported elevated emotional and attention difficulties; however, these appeared to be neither alleviated not exacerbated by their ill sibling's treatment. There was some evidence of worsening peer relationships, and from parent perspectives, there appeared to be an increasing awareness of siblings' emotional and social difficulties over the course of treatment. There was also evidence that sibling well-being was poorer for those whose brother or sister had been ill for longer.

At diagnosis, siblings reported poorer well-being in comparison to their peers as measured by elevated levels of emotional difficulties and hyperactivity/inattention. Emotional difficulties assessed by the SDQ include levels of worry, feelings of unhappiness and nervousness, fears, short temper, and somatic complaints (i.e. headaches, stomach aches and sickness). The hyperactivity/inattention scale assessed feelings of restlessness, fidgeting, being easily distracted, and thinking before acting.

The finding that siblings report poorer well-being in these areas is consistent with previous research which found that siblings of individuals with AN and children with chronic illness experience increased psychological difficulties (Areemit et al., 2010; Garley \& Johnson, 1994). While the findings may suggest that siblings are negatively 
impacted by having a brother or sister with AN, it is unknown if these difficulties predated the onset of the illness. Furthermore, environmental and genetic factors may contribute to a shared vulnerability to psychopathology in siblings (Becker, 2004; Bulik et al., 2006; Klump, Bulik, Kaye, Tyson, \& Treasure, 2009). However, longer duration of AN was associated with greater sibling emotional difficulties, providing some support for the theory that it is the illness impacting on sibling well-being. Interesting, there was little evidence that sibling well-being was related to other indicators of illness severity such as low weight and the presence of a psychiatric comorbidity, and siblings of patients who were hospitalised had better well-being than siblings of patients who were not hospitalised. However, hospitalised patients tended to have shorter duration of illness, possibly due to more acute weight loss leading to medical instability. The findings suggest it is longer exposure to the illness prior to diagnosis that is of more importance to sibling well-being, rather than the severity of the illness, although other indices of severity warrant further investigation. Of importance, following treatment, siblings' self-reported emotional difficulties and hyperactivity/inattention continued to be elevated compared to norms, but did not differ significantly from that of siblings at diagnosis. This suggests that FBT had neither a positive nor a negative effect on these aspects of sibling well-

being. However, following treatment siblings reported elevated peer problems compared to norms, a difference that was not apparent at diagnosis. Peer problems assessed by the SDQ include preferring to play alone and being bullied by others. The findings could suggest that siblings' difficulties with peers increased as treatment 
progressed, perhaps due to the illness or treatment contributing to social withdrawal from peers. It has been previously noted that siblings of adolescents with AN rely on family for emotional support, as stigma and ignorance of AN makes it difficult to speak to others about the disorder (Withers et al., 2013). Despite this finding, there were no significant differences in mean scores on peer problems between participants at diagnosis and following treatment. In addition, previous research has reported the SDQ peer problems subscale to have relatively poorer reliability (Giannakopoulos et al., 2013; Goodman, 2001), indicating that more research is needed in this area. In contrast to the findings for sibling self-report, prior to starting treatment, parents did not report that siblings were experiencing elevated emotional difficulties or hyperactivity/inattention. This discrepancy in findings between parents' and adolescents' reports is consistent with previous literature exploring the psychological adjustment of well siblings of children with a range of chronic illnesses (Guite, Lobato, Kao, \& Plante, 2004; Hollidge, 2000; Sawyer, Drew, Yeo, \& Britto, 2007; Sleeman, Northam, Crouch, \& Cameron, 2010; Taylor, Fuggle, \& Charman, 2001). Several explanations have been put forth for these inconsistencies including: parental desire to minimise the impact of negative events, inappropriate comparisons between unaffected and ill children, lack of recognition of emotional problems that the unaffected siblings may be experiencing, and siblings making a conscious effort to under-report their difficulties to parents in order to reduce the amount of stress placed on the parents (Sleeman et al., 2010). Of interest, at diagnosis, both mothers and fathers reported that siblings had lower levels of conduct problems in comparison to 
the general population which may support the hypothesis that siblings are attempting to reduce parents' stress by concealing their difficulties and being on their 'best behaviour'. Contrary to this, however, parents reported that siblings engaged in lower levels of prosocial behaviours, which could suggest that they were less aware of their unaffected children's behaviours generally. Notably, following treatment, mothers reported siblings to have greater emotional difficulties compared to norms and fathers reported lower prosocial behaviours compared to norms, differences that were not evident at diagnosis. While this may indicate that the treatment process negatively influenced sibling well-being, it may also be that parents developed a greater awareness of pre-existing difficulties over the course of treatment. These results should be treated with some caution given the low reliability coefficient for the parent-reported prosocial problems scale.

Despite the lack of evidence for a significant impact of treatment on sibling psychosocial well-being as measured by the SDQ, following treatment approximately one-third of siblings, patients, and fathers, and one-half of mothers were concerned that treatment had a negative effect on sibling well-being. It may be that the SDQ was not sensitive to family member's specific areas of concern or that there are subgroups of siblings for whom treatment posed challenges for their own well-being. A larger longitudinal study covering additional areas of functioning would help resolve this, and also clarify whether there are differences in expectations of treatment effects compared to perceptions following treatment. Although for the latter question, this study found no significant differences this may be due to limited sample sizes in some 
groups (e.g., fathers). In addition, it should be noted that the study-designed measure of family members' perception of treatment effects has not been validated and therefore may not accurately and reliably reflect experience.

Overall, the results suggest that siblings of adolescents with AN experience elevated psychosocial difficulties in comparison to their peers. These findings are consistent with previous literature, which suggests that siblings of adolescents with AN experience poorer quality of life (Areemit et al., 2010) and psychological difficulties such as problems coping with the illness (Garley \& Johnson, 1994). However, it is unknown whether factors such as age, gender, quality of sibling relationship, or level of involvement in the treatment process have an impact on overall sibling well-being. These moderators would need to be explored in further detail in future research to better understand the interaction between these factors and sibling overall well-being, both at diagnosis and at the end of treatment. The findings presented in this study support the need for research into the effect of AN on the entire family, especially long-term effects.

As the first study to explore the well-being of siblings of adolescents engaging in FBT, this research advances our understanding and has important implications for families and clinicians. As parents appear to underreport psychological difficulties experienced by siblings, clinicians are encouraged to provide some psychoeducation to the family as a whole about the process of treatment as well as the challenges that families are expected to face during the treatment process. Assessing sibling needs and developing treatment plans may be beyond the FBT clinician's scope given the 
already intense nature of the treatment. However, at the very least it may be beneficial for clinicians to be aware of referral pathways, which would enable siblings to receive support for difficulties they may be facing.

Despite the contribution of this study to the understanding of sibling wellbeing in the context of AN and FBT, some limitations should be acknowledged. First, as longitudinal data was not available, it is difficult to conclude whether sibling wellbeing was negatively influenced by the eating disorder or FBT, or whether difficulties were present before the onset of the illness. Additionally, although every attempt was made to collect data from families both before and after treatment, response rates were relatively low and sufficient numbers of matched families were not obtained for repeated-measures analysis. This is partly due to the timing of recruitment; that is, those who started treatment prior to study recruitment, and those who completed treatment after recruitment ceased, missed completing surveys before and after treatment, respectively. However, there may also be selection bias related to families refusing participation or withdrawing early from treatment. Future research using a larger sample with a repeated-measures design would allow for greater exploration of the effects of individual differences and moderating factors. Second, collection of data from other comparison samples would help to strengthen the study findings. For example, a control sample matched on age, gender, and other demographics, and samples of siblings of adolescents with other chronic illnesses and/or mental illnesses to determine whether the findings are specific to siblings of adolescents with AN. Third, all participants in this study were recruited from the same service. Although 
this increases the consistency of interventions, it may also limit the generalizability of these findings to other settings and services. Finally, the size of the sample and preponderance of female patients did not allow for examination of sex differences, such as differences in well-being between male and female siblings and effects for same-sex compared to opposite-sex sibling pairs. As there was some evidence that female siblings may experience poorer well-being than male siblings, further investigation of these effects would be worthwhile.

In conclusion, the present study offers some preliminary insights into unaffected siblings' well-being, and some of the difficulties that young people experience when they have a brother or sister with AN. Given the nature of AN and intensity of FBT, it may not always be possible for parents to allocate equal time and attention to unaffected siblings. However, the results of this study suggest that siblings have poorer well-being in comparison to their peers and as such, sibling wellbeing should be monitored and appropriate referrals made in a timely manner to ensure best possible outcomes for the siblings and the family as a whole.

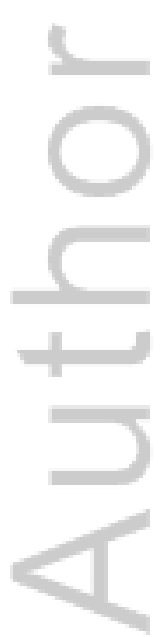




\section{Acknowledgements and Disclosure of Conflicts}

Daniel Le Grange receives royalties from Guilford Press and Routledge, and is codirector of the Training Institute for Child and Adolescent Eating Disorders, LLC. The remaining authors declare that they have no conflict of interests.

This research was funded by a University of Melbourne Early Career Researcher Grant (\#601000) awarded to Elizabeth Hughes. The Murdoch Childrens Research Institute is supported by the Victorian Government's Operational Infrastructure Support Program.

We would like to thank all the families that participated in this study and the team at the Royal Children's Hospital Eating Disorders Program for their support.

This article is protected by copyright. All rights reserved. 


\section{References}

Alderfer, M. A., Long, K. A., Lown, E., Marsland, A. L., Ostrowski, N. L., Hock, J. M., \& Ewing, L. J. (2010). Psychosocial adjustment of siblings of children with cancer: A systematic review. Psycho-Oncology, 19(8), 789-805.

American Psychiatric Association. (2000). Diagnostic and statistical manual of mental

= disorders (4th ed., text revision). Washington DC: American Psychiatric Press.

Areemit, R. S., Katzman, D. K., Pinhas, L., \& Kaufman, M. E. (2010). The experience of siblings of adolescents with eating disorders. Journal of Adolescent Health, 46(6), 569-576. doi: 10.1016/j.jadohealth.2009.12.011

Bachner-Melman, R. (2005). Siblings in the context of anorexia nervosa. The Israel Journal of Psychiatry and Related Sciences, 42(3), 178-184.

Barlow, J., \& Ellard, D. (2006). The psychosocial well-being of children with chronic disease, their parents and siblings: an overview of the research evidence base. Child Care, Health \& Development, 31(1), 19-31.

Barnable, A., Gaudine, A., Bennett, L., \& Meadus, R. (2006). Having a sibling with schizophrenia: a phenomenological study. Research and Theory for Nursing Practice, 20(3), 247-264.

Becker, A. E. (2004). Television, disordered eating, and young women in fiji: Negotiating body image and identity during rapid social change Culture, Medicine and Psychiatry, $28,533-559$.

This article is protected by copyright. All rights reserved. 
Bellin, M. H., \& Kovacs, P. J. (2006). Fostering resilience in siblings of youths with a chronic health condition: A review of the literature. Health and Social Work, 31(3), 209-216.

Bendor, S. J. (1990). Anxiety and isolation in siblings of pediatric cancer patients: The need for prevention. Social Work in Health Care, 14, 17-35.

Bulik, C. M., Sullivan, P., Fear, J., \& Joyce, P. (1997). Eating disorders and antecedent anxiety disorders: A controlled study. Acta Psychiatrica Scandinavica, 96(2), 101107. doi: 10.1111/j.1600-0447.1997.tb09913.x

Bulik, C. M., Sullivan, P. F., Tozzi, F., Furberg, H., Lichtenstein, P., \& Pedersen, N. L. (2006). Prevalence, heritability, and prospective risk factors for anorexia nervosa. Archives of General Psychiatry, 63(3), 305-312. doi: 10.1001/archpsyc.63.3.305

Ciao, A. C., Accurso, E. C., Fitzsimmons-Craft, E. E., Lock, J., \& Le Grange, D. (2014). Family functioning in two treatments for adolescent anorexia nervosa. International Journal of Eating Disorders, n/a-n/a. doi: 10.1002/eat.22314

Dare, C., Eisler, I., Russell, G. F. M., \& Szmukler, G. I. (1990). The clinical and theoretical impact of a controlled trial of family therapy in anorexia nervosa. Journal Of Marital and Family Therapy., 16, 39-57.

Del Rosario, B., \& Keefe, E. (2003). Effects of sibling relationship with a child with severe disabilities on the child without disabilities: A review of research. Developmental Disabilities Bulletin, 31(2), 102-129.

This article is protected by copyright. All rights reserved. 
Dimitropoulos, G., Klopfer, K., Lazar, L., \& Schacter, R. (2009). Caring for a sibling with anorexia nervosa: A qualitative study. European Eating Disorders Review, 17(5), $350-365$.

Eisler, I., Simic, M., Russell, G. F., \& Dare, C. (2007). A randomised controlled treatment trial of two forms of family therapy in adolescent anorexia nervosa: A five-year follow-up. Journal of Child Psychology \& Psychiatry \& Allied Disciplines, 48(6), $552-560$.

Faux, S. (1991). Sibling relationships in families with congenitally impaired children. Journal of Pediatric Nursing, 6(3), 175-184.

Faux, S. (1993). Siblings of children with chronic physical and cognitive disabilities. Journal of Paediatric Nursing, 8, 305-317.

Ferrari, M. (1983). Chronic illness: Psychosocial effects on siblings. Journal of Child Psychology 25, 215-229.

Ferrari, M. (1987). The diabetic child and well sibling: Risks to the well child's self concept. Children's Health Care, 15(3), 141-148.

Garley, D., \& Johnson, B. (1994). Siblings and eating disorders: a phenomenological perspective. Journal of Psychiatric and Mental Health Nursing, 1(3), 157-164.

Giallo, R., \& Gavidia-Payne, S. (2006). Child, parent and family factors as predictors of adjustment for siblings of children with a disability. Journal of Intellectual Disability Research, 50(12), 937-948.

Giannakopoulos, G., Dimitrakaki, C., Papadopoulou, K., Tzavara, C., Kolaitis, G., RavensSieberer, U., \& Tountas, Y. (2013). Reliability and validity of the Strengths and

This article is protected by copyright. All rights reserved. 
Difficulties Questionnaire in Greek adolescents and their parents. Scientific Research: Health, 5(11), 1774-1783. doi: 10.4236/health.2013.511239

Goodman, R. (2001). Psychometric properties of the Strengths and Difficulties Questionnaire. Journal of the American Academy of Child \& Adolescent Psychiatry $40,1137-1345$.

Guite, J., Lobato, D. J., Kao, B. T., \& Plante, W. (2004). Discordance between sibling and parent reports of the impact of chronic illness and disability on siblings. Journal of Child Health Care, 33, 77-92

Herzog, D. B., Keller, M. B., Sacks, N. R., Yeh, C. J., \& Lavori, P. W. (1992). Psychiatric comorbidity in treatment-seeking anorexics and bulimics. Journal of the American Academy of Child and Adolescent Psychiatry, 31(5), 810-818.

Hoek, H. W., \& van Hoeken, D. (2003). Review of the prevalence and incidence of eating disorders. International Journal of Eating Disorders, 34(4), 383-396. doi:

10.1002/eat.10222

Hollidge, C. (2000). Well children living with diabetic siblings: implications for emotional adjustment utilising a psychodynamic framework. Journal of Analytical Social Work, 7, 49-74.

Honey, A., Clarke, S., Halse, C., Kohn, M., \& Madden, S. (2006). The influence of siblings on the experience of anorexia nervosa for adolescent girls. European Eating Disorders Review, 14(5), 315-322. doi: 10.1002/erv.713

Honey, A., \& Halse, C. (2007). Looking after well siblings of adolescent girls with anorexia: an important parental role. Child: Care, Health and Development, 33(1), 52-58.

This article is protected by copyright. All rights reserved. 
Horwitz, W., \& Kazak, A. (1990). Family adaptation to childhood cancer: Sibling and family systems variables. Journal of Clinical Child Psychology, 19(3), 221-228.

Karp, D. A., \& Tanarugsachock, V. (2000). Mental illness, caregiving, and emotion management. Qualitative Health Research, 10, 6-25.

Klump, K. L., Bulik, C. M., Kaye, W. H., Tyson, E., \& Treasure, J. (2009). Academy for Eating Disorders position paper: Eating disorders are serious mental illnesses. International Journal of Eating Disorders, 42(2), 97-103.

Kramer, R. (1984). Living with childhood cancer: Impact on the healthy siblings. Oncology Nursing Forum, 11, 44-51.

Labay, L. E., \& Walco, G. A. (2004). Brief Report: Empathy and psychological adjustment in siblings of children with cancer. Journal of Pediatric Psychology, 29(4), 309-314.

Lilenfeld, L. R., Kaye, W. H., Greeno, C. G., \& et al. (1998). A controlled family study of anorexia nervosa and bulimia nervosa: Psychiatric disorders in first-degree relatives and effects of proband comorbidity. Archives of General Psychiatry, 55(7), 603-610. doi: 10.1001/archpsyc.55.7.603

Lively, S., Friedrich, R. M., \& Rubenstein, L. (2004). The effect of disturbing illness behaviors on siblings of persons with schizophrenia. Journal of the American Psychiatric Nurses Association, 10, 222-232.

Lock, J. (2015). An Update on Evidence-Based Psychosocial Treatments for Eating Disorders in Children and Adolescents. Journal of Clinical Child \& Adolescent Psychology, 115. doi: $10.1080 / 15374416.2014 .971458$

This article is protected by copyright. All rights reserved. 
Lock, J., \& Le Grange, D. (2013). Treatment manual for anorexia nervosa: A family-based approach (2nd ed.). New York: Guilford Press.

Lock, J., Le Grange, D., Agras, W. S., Moye, A., Bryson, S. W., \& Jo, B. (2010).

Randomized clinical trial comparing family-based treatment with adolescent-focused individual therapy for adolescents with anorexia nervosa. Archives of General Psychiatry, 67(10), 1025-1032. doi: 10.1001/archgenpsychiatry.2010.128

Marsh, D. T., Dickens, R. M., Koeske, R. D., Yachovich, N. S., Wilson, J. M., Leichliter, J. S., \& McQuillis, V. (1994). Troubled journey: Siblings and children of people with mental illness. Innovations and Research, 2, 13-23.

McHale, S. M., Sloan, J., \& Simeonsson, R. J. (1986). Sibling relations of children with autistic, mentally retarded, and non-handicapped brothers and sisters Journal of Autism and Developmental Disorders, 16, 399-413.

Mitchell, J. E., \& Crow, S. (2006). Medical complications of anorexia nervosa and bulimia nervosa. Current Opinion in Psychiatry, 19(4), 438-443. doi:

10.1097/01.yco.0000228768.79097.3e

Moorman, M. (1992). My sister's keeper: Learning to cope with a sibling's mental illness. New York: W. W. Norton

Powell, T. H., \& Gallagher, P. A. (1993). Brothers \& sisters: A special part of exceptional families (2nd ed.). Baltimore, MD: Paul H. Brookes.

Robin, A. L., Siegel, P. T., Koepke, T., Moye, A. W., \& Tice, S. (1994). Family therapy versus individual therapy for adolescent females with anorexia nervosa. Journal of

This article is protected by copyright. All rights reserved. 
Developmental and Behavioral Pediatrics, 15(2), 111-116. doi: 10.1097/00004703199404000-00008

Robin, A. L., Siegel, P. T., Moye, A. W., Gilroy, M., Baker Dennis, A., \& Sikand, A. (1999). A controlled comparison of family versus individual therapy for adolescents with anorexia nervosa. Journal of the American Academy of Child \& Adolescent Psychiatry, 38(12), 1482-1489.

Russell, G. F., Szmukler, G. I., Dare, C., \& Eisler, I. (1987). An evaluation of family therapy in anorexia nervosa and bulimia nervosa. Archives of General Psychiatry, 44(12), $1047-1056$.

Sawyer, S., Drew, S., Yeo, M., \& Britto, M. (2007). Adolescents with a chronic condition: challenges living, challenges treating. The Lancet, 369(9571), 1481-1489. doi: 10.1016/S0140-6736(07)60370-5

Seltzer, M. M., Greenberg, J. S., Krauss, M. W., Gordon, R. M., \& Judge, K. (1997). Siblings of Adults with Mental Retardation or Mental Illness: Effects on Lifestyle and Psychological Well-Being. Family Relations, 46(4), 395-405.

Sharpe, D., \& Rossiter, L. (2002). Siblings of children with a chronic illness: A meta analysis. Journal of Pediatric Psychology, 27(8), 699-710.

Sleeman, F., Northam, E. A., Crouch, W., \& Cameron, F. J. (2010). Psychological adjustment of well siblings of children with Type 1 diabetes Diabetic Medicine, 1084-1087.

Sloper,P. (2000). Experiences and support needs of siblings of children with cancer. Health and Social Care in the Community, 8(5), 298-306.

This article is protected by copyright. All rights reserved. 
Sullivan, P. F., Bulik, C. M., Fear, J., \& Pickering, A. (1998). Outcome of anorexia nervosa. American Journal of Psychiatry 155, 939-946.

Swanson, S. A., Crow, S. J., Le Grange, D., Swendsen, J., \& Merikangas, K. R. (2011). Prevalence and correlates of eating disorders in adolescents: Results from the national comorbidity survey replication adolescent supplement. Archives of General Psychiatry, 68(7), 714-723. doi: 10.1001/archgenpsychiatry.2011.22

Taylor, V., Fuggle, P., \& Charman, T. (2001). Well sibling psychological adjustment to chronic physical disorder in a sibling: how important is maternal awareness of their illness attitudes and perceptions? Journal of Child Psychology and Psychiatry, 42, $953-962$.

Tritt, S., \& Esses, L. (1988). Psychosocial adaptation of siblings of children with chronic medical illness. American Journal of Orthopsychiatry, 58(2), 211-220.

Withers, A., Mullan, B., Madden, S., Kohn, M., Clarke, S., Thornton, C., . . Touyz, S. (2013). Anorexia nervosa in the family: a sibling's perspective. Advances in Eating Disorders, 2(1), 53-64. doi: 10.1080/21662630.2013.839187

Wood, B., Boyle, J., Watkins, J., Nogueira, J., Zimand, E., \& Carrol, L. (1988). Sibling psychological status and style as related to the disease of their chronically ill brothers and sisters: Implications for models of biopsychosocial interaction. Developmental and Behavioral Pediatrics, 9(2), 66-72.

This article is protected by copyright. All rights reserved. 
Table 1

Demographic data of the Study Sample

At diagnosis

Following treatment

\begin{tabular}{|c|c|c|c|c|c|}
\hline $\mathrm{N}$ & Age, M (SD) & Female, n (\%) & $\mathrm{N}$ & Age, $\mathrm{M}(\mathrm{SD})$ & Female, n (\%) \\
\hline Siblings & $16.4(4.3)$ & $31(56.4 \%)$ & 46 & $16.4(3.5)$ & $28(60.9 \%)$ \\
\hline Mothers 47 & $46.6(6.0)$ & & 64 & 46.7 (4.8) & \\
\hline Fathers $\quad 38$ & $47.6(9.3)$ & & 24 & $48.9(5.6)$ & \\
\hline Patients & 15.4 (1.7) & $43(91.5 \%)$ & 38 & $16.1(1.8)$ & $35(92.1 \%)$ \\
\hline
\end{tabular}

This article is protected by copyright. All rights reserved. 
Table 2

Comparison of SDQ Scores of the Study Samples at Diagnosis and Following Treatment with Population Norms

\begin{tabular}{|c|c|c|c|c|c|c|c|}
\hline & \multirow[b]{4}{*}{ SDQ subscale } & Study Sample & \multicolumn{5}{|l|}{ Study Sample } \\
\hline & & at Diagnosis & Following & \multicolumn{4}{|l|}{ Norm Sample } \\
\hline & & (A) & Treatment (B) & (C) & A vs $\mathrm{C}$ & B vs $\mathrm{C}$ & A vs B \\
\hline & & $\mathrm{M}(\mathrm{SD})$ & $\mathrm{M}(\mathrm{SD})$ & $\mathrm{M}(\mathrm{SD})$ & $\mathrm{p}$ value & $\mathrm{p}$ value & $\mathrm{p}$ value \\
\hline Siblings & Emotional Difficulties & $3.67(2.68)$ & $3.87(2.54)$ & $2.4(2.0)$ & $<.001$ & $<.001$ & .703 \\
\hline & Conduct Problems & $1.65(2.00)$ & $1.89(1.49)$ & $1.8(1.7)$ & .540 & .728 & .503 \\
\hline & Hyperactivity/Inattention & $4.00(2.29)$ & $3.89(2.14)$ & $3.2(2.3)$ & .014 & .050 & .805 \\
\hline & Peer Problems & $1.65(1.99)$ & $2.30(1.53)$ & $1.5(1.6)$ & .518 & $<.01$ & .073 \\
\hline & Prosocial Behaviours & $8.09(1.60)$ & $7.91(1.86)$ & $8.0(1.7)$ & .707 & .732 & .602 \\
\hline & Total difficulties & $10.98(6.85)$ & $11.96(5.75)$ & $9.0(5.6)$ & .015 & $<.001$ & .443 \\
\hline Mothers & Emotional Difficulties & $2.43(2.38)$ & $2.95(2.89)$ & $2.1(2.0)$ & .275 & $<.01$ & .316 \\
\hline
\end{tabular}




\begin{tabular}{|c|c|c|c|c|c|c|c|}
\hline \multirow{5}{*}{$=$} & & Study Sample & Study Sample & & & & \\
\hline & & at Diagnosis & Following & Norm Sample & & & \\
\hline & & (A) & Treatment (B) & (C) & A vs $\mathrm{C}$ & B vs C & A vs $B$ \\
\hline & SDQ subscale & $\mathrm{M}(\mathrm{SD})$ & $\mathrm{M}(\mathrm{SD})$ & $\mathrm{M}(\mathrm{SD})$ & $\mathrm{p}$ value & $\mathrm{p}$ value & $\mathrm{p}$ value \\
\hline & Conduct Problems & $0.89(1.20)$ & $1.34(1.54)$ & $1.5(1.6)$ & .010 & .439 & .099 \\
\hline
\end{tabular}


Table 2 cont.

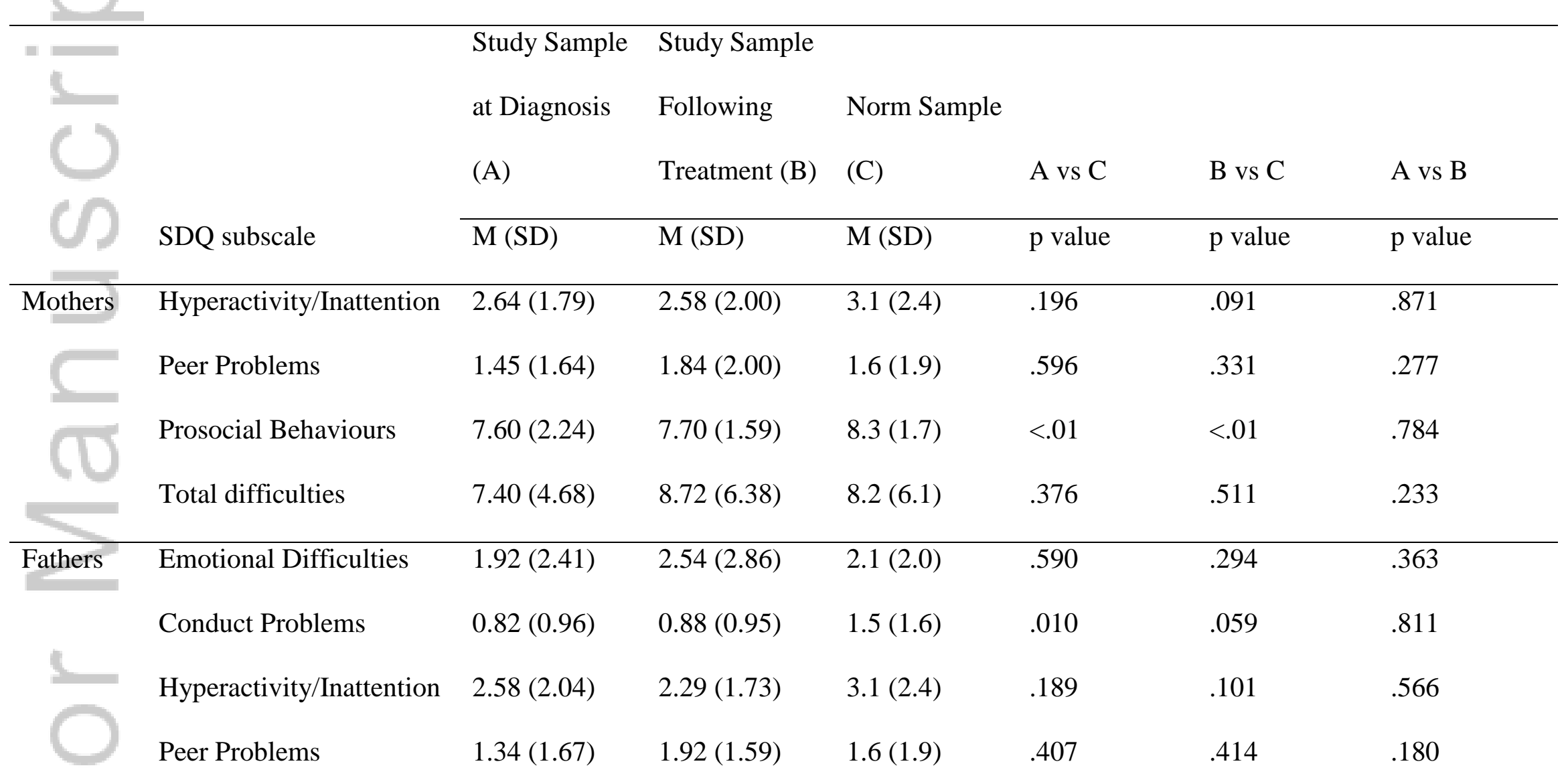




\begin{tabular}{|c|c|c|c|c|c|c|c|}
\hline \multirow{6}{*}{$=$} & & Study Sample & Study Sample & & & & \\
\hline & & at Diagnosis & Following & Norm Sample & & & \\
\hline & & (A) & Treatment (B) & (C) & A vs $\mathrm{C}$ & B vs C & A vs $B$ \\
\hline & SDQ subscale & $\mathrm{M}(\mathrm{SD})$ & $\mathrm{M}(\mathrm{SD})$ & $\mathrm{M}(\mathrm{SD})$ & $\mathrm{p}$ value & $\mathrm{p}$ value & $\mathrm{p}$ value \\
\hline & Prosocial Behaviours & $7.84(1.85)$ & $7.29(1.90)$ & $8.3(1.7)$ & .104 & .004 & .264 \\
\hline & Total difficulties & $6.66(5.28)$ & $7.63(5.33)$ & $8.2(6.1)$ & .126 & .651 & .485 \\
\hline
\end{tabular}


Table 3 Pearson's correlations between SDQ scores and patient percent of median BMI (\%mBMI) and duration of illness at diagnosis
SDQ subscale
$\% \mathrm{mBMI}$
Duration of Illness

\begin{tabular}{|c|c|c|c|}
\hline Siblings & Emotional Difficulties & -.01 & $.36 * *$ \\
\hline & Conduct Problems & -.11 & -.04 \\
\hline & Hyperactivity/Inattention & -.12 & .09 \\
\hline & Peer Problems & -.20 & .21 \\
\hline & Prosocial Behaviours & .21 & -.01 \\
\hline & Total difficulties & -.13 & $.24 *$ \\
\hline Mothe & Emotional Difficulties & .03 & $.37 * *$ \\
\hline & Conduct Problems & -.17 & .05 \\
\hline & Hyperactivity/Inattention & -.15 & .07 \\
\hline & Peer Problems & -.12 & $.37 * *$ \\
\hline & Prosocial Behaviours & .21 & -.17 \\
\hline & Total difficulties & -.13 & $.36 * *$ \\
\hline Fathers & Emotional Difficulties & .23 & $.49 * * *$ \\
\hline & Conduct Problems & -.04 & -.07 \\
\hline & Hyperactivity/Inattention & -.17 & .13 \\
\hline & Peer Problems & .08 & $.41 * *$ \\
\hline & Prosocial Behaviours & .11 & $-.32 *$ \\
\hline & Total difficulties & .06 & $.38 * *$ \\
\hline
\end{tabular}

Note.

This article is protected by copyright. All rights reserved. 
$* p<.05, * * p<.01, * * * p<.001$.

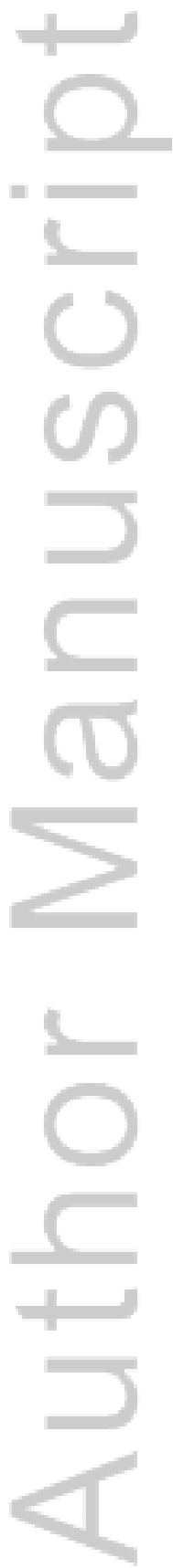

This article is protected by copyright. All rights reserved. 
Table 4 Comparison of SDQ scores (at diagnosis) for siblings of patient who were hospitalised and not hospitalised at presentation

\section{Not}

Hospitalised Hospitalised

\begin{tabular}{|c|c|c|c|c|}
\hline \multirow{2}{*}{4} & \multirow[b]{2}{*}{ SDQ subscale } & \multirow{2}{*}{$\mathrm{M}(\mathrm{SD})$} & & \multirow[b]{2}{*}{$\mathrm{p}$ value } \\
\hline & & & $\mathrm{M}(\mathrm{SD})$ & \\
\hline \multicolumn{5}{|c|}{ At diagnosis } \\
\hline \multirow[t]{6}{*}{ Siblings } & Emotional Difficulties & $2.88(1.75)$ & $4.44(2.81)$ & .003 \\
\hline & Conduct Problems & $1.46(1.48)$ & $1.70(1.94)$ & .576 \\
\hline & Hyperactivity/Inattention & $3.23(2.14)$ & $4.47(2.05)$ & .013 \\
\hline & Peer Problems & $1.69(1.89)$ & $1.56(1.85)$ & .767 \\
\hline & Prosocial Behaviours & $8.08(1.81)$ & $8.26(1.41)$ & .611 \\
\hline & Total difficulties & $9.27(5.06)$ & $12.18(6.50)$ & .047 \\
\hline \multirow[t]{3}{*}{ Mothers } & Emotional Difficulties & $1.52(1.70)$ & $2.85(2.54)$ & .010 \\
\hline & Conduct Problems & $0.74(0.92)$ & $0.92(1.27)$ & .529 \\
\hline & Hyperactivity/Inattention & $2.39(1.53)$ & $2.87(1.92)$ & .296 \\
\hline \multirow[t]{3}{*}{1} & Peer Problems & $1.30(1.11)$ & $1.60(1.81)$ & .465 \\
\hline & Prosocial Behaviours & $7.48(2.09)$ & $7.81(2.03)$ & .517 \\
\hline & Total difficulties & $5.96(3.02)$ & $8.25(5.02)$ & .017 \\
\hline \multirow[t]{4}{*}{ Fathers } & Emotional Difficulties & $1.17(1.74)$ & $2.76(2.86)$ & .009 \\
\hline & Conduct Problems & $0.63(0.65)$ & $1.03(1.14)$ & .123 \\
\hline & Hyperactivity/Inattention & $2.08(1.74)$ & $2.70(2.22)$ & .253 \\
\hline & Peer Problems & $1.04(1.43)$ & $1.65(1.77)$ & .164 \\
\hline
\end{tabular}

This article is protected by copyright. All rights reserved. 
Hospitalised Hospitalised

SDQ subscale

$\mathrm{M}(\mathrm{SD}) \quad \mathrm{M}(\mathrm{SD}) \quad \mathrm{p}$ value

Prosocial Behaviours

$8.04(1.63) \quad 7.84(1.98) \quad .676$

Total difficulties

$4.92(3.66)$

$8.14(6.30)$

.014

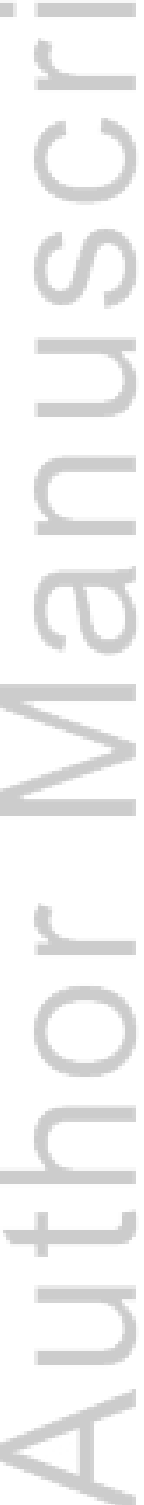

This article is protected by copyright. All rights reserved. 
Table 5

Comparison of Parent, Sibling, and Patient Expectations (at Diagnosis) and Perceptions (Following Treatment) of the Impact of the Patient's Treatment on Sibling Overall Wellbeing

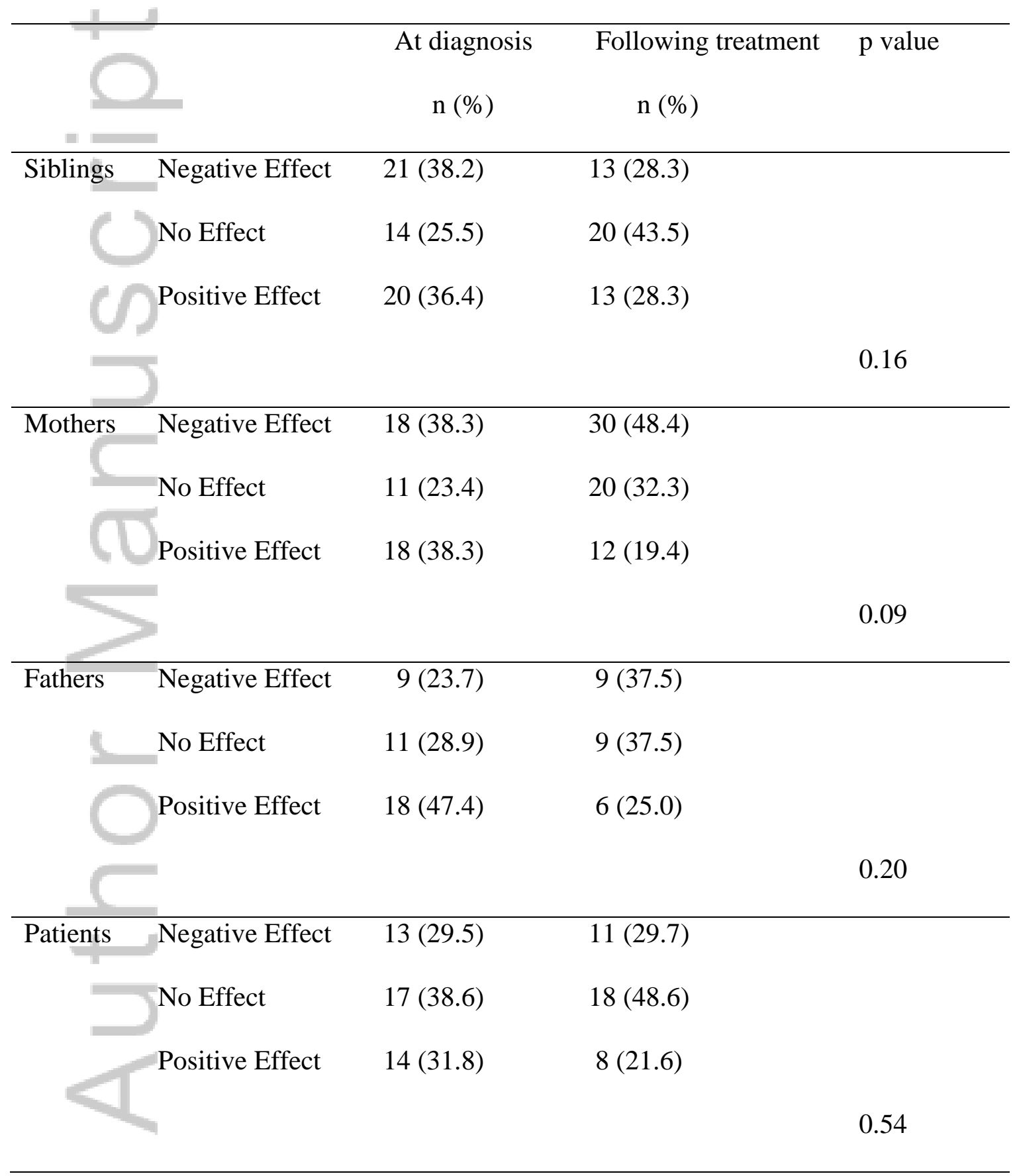

This article is protected by copyright. All rights reserved. 


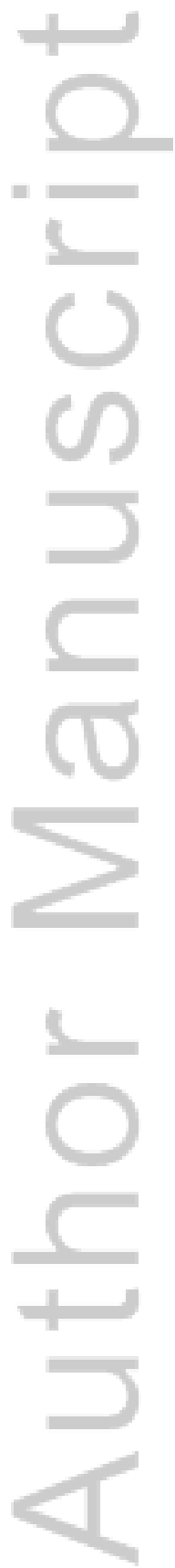

This article is protected by copyright. All rights reserved. 


\section{University Library}

\section{- M M N E R VA A gateway to Melbourne's research publications}

Minerva Access is the Institutional Repository of The University of Melbourne

\section{Author/s:}

van Langenberg, T;Sawyer, SM;Le Grange, D;Hughes, EK

Title:

Psychosocial Well-being of Siblings of Adolescents with Anorexia Nervosa

\section{Date:}

2016-11-01

Citation:

van Langenberg, T., Sawyer, S. M., Le Grange, D. \& Hughes, E. K. (2016). Psychosocial Well-being of Siblings of Adolescents with Anorexia Nervosa. EUROPEAN EATING DISORDERS REVIEW, 24 (6), pp.438-445. https://doi.org/10.1002/erv.2469.

Persistent Link:

http://hdl.handle.net/11343/291598 